\title{
Indução de Resistência a Fusarium Oxysporum f. sp. Tracheiphilum em Caupi: Eficiência de Indutores Abióticos e Atividade Enzimática Elicitada
}

\author{
Antonia Alice C. Rodrigues ${ }^{1}$, Egídio B. Neto $^{2} \&$ Rildo S.B. Coelho ${ }^{2}$ \\ ${ }^{1}$ Departamento de Fitotecnia e Fitossanidade/Laboratório de Fitopatologia, Universidade Estadual do Maranhão, \\ Cx. Postal 09, São Luís, MA, CEP 65000-970, e-mail:alicecosta@cca.uema.br; ${ }^{2}$ Departamento de Agronomia; \\ Departamento de Química/Laboratório de Bioquímica Vegetal, Universidade Federal Rural de Pernambuco,
}

CEP 52171-900, Recife, PE

(Aceito para publicação em 23/06/2006)

Autor para correspondência: Antonia Alice C. Rodrigues

RODRIGUES, A.A.C.; BEZERRA NETO, E. \& COELHO, R.S.B. Indução de resistência a Fusarium oxysporum f. sp. tracheiphilum em caupi: eficiência de indutores abióticos e atividade enzimática elicitada. Fitopatologia Brasileira 31:492499. 2006.

\section{RESUMO}

Foram avaliados os efeitos de indutores abióticos em cultivares de caupi inoculadas com Fusarium oxysporum $\mathrm{f}$. sp. tracheiphilum quanto à severidade, controle da doença e atividade enzimática. Para isso, plantas das cultivares IPA-206 e BR-17 Gurguéia com cinco dias de idade foram pulverizadas com soluções aquosas de ASM (5,0 g do i.a./100 L de água), BABA $(1,5 \mathrm{mM})$ e quitosana $(2,0 \mathrm{mg} / \mathrm{mL})$, no primeiro par de folhas e inoculadas, após sete dias da germinação, com $20 \mathrm{~mL}$ de uma suspensão de 1 x $10^{6}$ conídios/mL do isolado ISO-PE. A avaliação da severidade da doença foi realizada aos 25 dias após a germinação, através de escala de notas e índice de doença. As atividades das enzimas $\beta$-1,3-glucanase, peroxidase e fenilalanina amônia liase (PAL) foram determinadas em plantas submetidas aos tratamentos anteriores, coletadas aos cinco e 10 dias após a inoculação. Foi observada diferença significativa entre os indutores e a testemunha, nas duas cultivares testadas, aos cinco e 10 dias, destacando-se o indutor ASM, proporcionando um controle da doença de 68,90\% e 71,59\% nas cultivares BR-17 Gurguéia e IPA-206, respectivamente. O indutor ASM apresentou melhores resultados nas atividades de $\beta$-1,3-glucanase, peroxidase e PAL, destacando-se na cultivar IPA-206 nos dois períodos analisados. Os indutores BABA e quitosana diferiram da testemunha, na atividade de PAL e $\beta$-1,3-glucanase, nessa mesma cultivar, aos cinco dias após a inoculação.

Palavras-chave adicionais: Murcha de Fusarium, $\beta$-1,3-glucanase, peroxidase, fenilalanina amônia liase, resistência sistêmica adquirida.

\begin{abstract}
Induced resistance to Fusarium oxysporum f. sp. tracheiphilum in cowpea plants: effectiveness of abiotic inducers and elicited enzymatic activity

The effect of abiotic inducers in two cowpea cultivars inoculated with Fusarium oxysporum f.sp. tracheiphilum (E. F. Smith) Snyder \& Hansen was evaluated in relation to severity, disease control and enzyme activity. Aqueous solution of $\operatorname{ASM}(5.0 \mathrm{mg} / \mathrm{mL}), \operatorname{BABA}(1.5 \mathrm{mM})$ or chitosan $(2.0 \mathrm{mg} / \mathrm{mL})$ was sprayed on the first pair of leaves of five-day-old cowpea plants, cultivars BR-17 Gurguéia and IPA-206. After seven days of elicitor application, inoculation was carried out with 20 $\mathrm{mL}$ of a $1 \times 10^{6}$ conidia/mL suspension of the ISO-PE isolate. Plants were harvested at five and 10 days after inoculation, and the activity of phenylalanine ammonia lyase (PAL), $\beta$-1.3-glucanase and peroxidase was analyzed. Significant difference between treatment with inducers and control was verified, mainly for ASM which provided a disease control of $68.9 \%$ and $71.59 \%$ for BR-17 Gurguéia and IPA-206 cultivars, respectively. ASM showed the best results related to $\beta$-1.3-glucanase, peroxidase and PAL and activities, especially for the cultivar IPA-206 five or 10 days. BABA and chitosan differed from the control for PAL and $\beta$-1.3-glucanase activity on cultivar IPA-206, five days after inoculation.

Additional keywords: Fusarium wilt, $\beta$-1.3-glucanase, peroxidase, phenylalanine ammonia lyase, systemic acquired resistance.
\end{abstract}

\section{INTRODUÇÃO}

Durante a interação patógeno-hospedeiro ocorre a ativação do sistema de defesa da planta por vários meios, resultando na produção de substâncias tóxicas aos patógenos, impedindo o estabelecimento destes. Alguns compostos produzidos pelas plantas possuem ação antimicrobiana, enquanto outros restringem o desenvolvimento de patógenos pela formação de barreiras estruturais (Oliveira et al., 2001). Conforme Durrant \& Dong (2004) a resistência sistêmica adquirida (RSA), caracteriza-se pela expressão de genes relacionados com a produção de proteínas PR (relacionadas com a patogênese), consideradas como importantes fatores na resistência de plantas a diversas classes de fitopatógenos, incluindo fungos, bactérias, vírus e oomicetos. Os genes envolvidos nas diferentes rotas de síntese de substâncias de 
defesa, assim como as interações entre as rotas envolvendo o ácido salicílico (AS) e jasmonato/etileno, têm importância significativa no processo de sinalização que leva à RSA .

A expressão de RSA tem sido observada com o uso de vários produtos químicos ou abióticos, assim como o uso de microrganismos não patogênicos e condições de estresse. Esse tipo de reação já foi estudado em vários patossistemas, envolvendo principalmente, hospedeiros como pepino (Cucumis sativus L.), Arabidopsis thaliana (L.) Heynh., e fumo ( Nicotiana tabacum L.), que servem como modelos para o entendimento do processo de resistência à infecção de vários patógenos (Hammerschmidt, 2001).

A RSA pode ser aumentada pelo uso de indutores abióticos, os quais ativam o sistema de defesa das plantas, envolvendo várias etapas e rotas, potencializadas após a interação com o patógeno. Dentre os indutores mais utilizados, destacam-se o Acibenzolar-S-methil (ASM), ácido $\beta$-aminobutírico (BABA) e quitosana (Benhamou et al., 1998; Cole, 1999; Jakab et al., 2001), porém, apenas o ASM é liberado para uso comercial (Resende et al., 2000).

Os indutores podem atuar de diferentes formas, porém, sempre levando à ativação do sistema de defesa das plantas. O ASM é um análogo do AS, que age induzindo a ativação de genes que codificam proteínas PR e enzimas relacionadas com a produção de fitoalexinas e lignina (Cole, 1999; Resende et al., 2000). Provavelmente, o BABA induz a produção de proteínas $\mathrm{PR}$, como ocorre com o ASM (Jakab et al., 2001), enquanto que a ação da quitosana pode se dar através da criação de uma barreira estrutural, pela lignificação da parede celular, ou pelo efeito inibitório sobre o crescimento de fungos fitopatogênicos (Benhamou et al., 1998).

Dentre as proteínas PR ativadas pelos indutores encontram-se as hidrolases $\beta$-1,3-glucanase e quitinase, que promovem a desorganização da parede celular dos patógenos, as peroxidases, e a fenilalanina amônia liase (PAL), que estão diretamente envolvidas no processo de lignificação da parede celular (Oliveira et al., 2001). Dann \& Deverall (2000) observaram a ativação da resistência sistêmica em ervilha a Uromyces viciae-fabae (Pers.) J. Schroet, quando as plantas foram tratadas com altas dosagens de ASM e isolados avirulentos de Pseudomonas syringae pv. pisi (Sackett) Young, Dye \& Wilkie, associadas ao aumento da atividade de $\beta$-1,3-glucanase e peroxidase.

Em caupi [Vigna unguiculata (L.) Walp.], plântulas tratadas com ASM e inoculadas com Colletotrichum destructivum O'Gara apresentaram aumento da resistência, comprovada com o aumento das enzimas PAL e chalcone isomerase (Latunde-Dada \& Lucas, 2001).

A murcha de fusário do caupi, causada por Fusarium oxysporum f. sp. tracheiphilum (E.F. Smith) W.C. Snyder \& H.N. Hansen, destaca-se como importante doença na cultura do caupi no Nordeste brasileiro, podendo causar reduções na produção de sementes de até $86 \%$ em cultivares suscetíveis (Assunção et al., 2003). Neste patossistema, o uso de cultivares resistentes tem sido a única alternativa eficiente de controle. No entanto, dificuldades na obtenção dessas cultivares e uso da resistência do tipo raça-específica, de pouca durabilidade, justificam a busca de alternativas viáveis de controle desta doença. Com base no exposto, o trabalho teve como objetivo avaliar a eficiência de indutores abióticos na redução da severidade da murcha de fusário e determinar a atividade das enzimas $\beta$-1,3-glucanase, peroxidase e fenilalanina amônia liase em plantas de caupi induzidas com ASM, BABA e quitosana.

\section{MATERIAL E MÉTODOS}

Efeito de indutores em plantas de caupi inoculadas com Fusarium oxysporum f. sp. tracheiphilum

Os tratamentos constaram de um arranjo fatorial de $2 \times 2 \times 4$, sendo duas cultivares, duas épocas de coleta das folhas e três indutores e a testemunha inoculada somente com o patógeno.

As cultivares de caupi, IPA-206, com padrão de resistência intermediária, e BR-17 Gurguéia, suscetível a $F$. oxysporum f. sp. tracheiphilum (Albuquerque et al., 2001), foram semeadas em vasos plásticos, com capacidade de 3 $\mathrm{dm}^{3}$, contendo solo esterilizado com brometo de metila, mantendo-se, após o desbaste, três plantas/vaso.

Os indutores consistiram em dosagens de acibenzolarS-metil (ASM), ácido $\beta$-aminobutírico (BABA) e quitosana purificada de acordo com Benhamou et al. (1998). Estes foram aplicados por pulverização, no primeiro par de folhas aos cinco dias, após a germinação. ASM, formulado com 50 $\%$ do i.a. em grânulos (BION WG 50 ), obtido da Novartis Crop Protection, foi aplicado na concentração de 5,0 mg do i.a. $\mathrm{mL}^{-1}$ de água. Os indutores BABA e quitosana, ambos da Sigma Chemical, foram aplicados, respectivamente, nas concentrações de $1,5 \mathrm{mM}$ e $2 \mathrm{mg} / \mathrm{mL}$.

Aos sete dias após a germinação, foi realizada a inoculação, sendo utilizado um isolado de $F$. oxysporum f. sp. tracheiphilum, obtido de planta de caupi infectada, proveniente do município de Floresta-PE (ISO-PE). Na produção do inóculo, o isolado foi repicado para placa de Petri contendo meio BDA e incubado à temperatura ambiente. Foram adicionados $20 \mathrm{~mL}$ de água destilada esterilizada em cada placa e a superfície das colônias raspadas com lâminas de vidro. A suspensão de conídios foi filtrada em gaze dupla e ajustada para $1 \times 10^{6}$ conídios. $\mathrm{mL}^{-1}$, com auxílio de câmara de Neubauer. Foi adotado o método de inoculação por ferimento na raiz (Menezes, 1972) adicionando-se $20 \mathrm{~mL}$ da suspensão por planta.

As épocas de coleta foram aos cinco e 10 dias após a inoculação do patógeno, reservando-se uma planta para cada período de coleta. A severidade da doença foi avaliada aos 25 dias após a germinação, utilizando-se três plantas, através de escala de notas de 1 a 9 , onde 1 significa nenhum sintoma visível, e 9 aproximadamente $75 \%$ ou mais das folhas exibindo murcha, nanismo severo e necrose com desfolhação, causando a morte de plantas (Schoonhoven \& Pastor-Corrales, 1987). Utilizou-se também o índice de 
Mackinney (Balardin et al., 1990) e estimou-se a percentagem de controle da doença, considerando cada tratamento em relação a respectiva testemunha.

O delineamento experimental utilizado foi inteiramente casualizado, com quatro repetições, sendo que cada unidade experimental constou de um vaso com três plantas. Os dados foram analisados pelo programa estatístico SANEST, transformados em $(\mathrm{x}+0,5)^{1 / 2} \mathrm{e}$ as médias comparadas de acordo com Tukey ao nível de $5 \%$ de probabilidade.

\section{Determinação da Atividade Enzimática Preparação do extrato enzimático}

Amostras de 1,0 g de folhas correspondendo a cada tratamento foram maceradas em almofariz com nitrogênio líquido com $1 \%(\mathrm{v} / \mathrm{v})$ de polivinilpirrolidone (PVP) e 1,0 $\mathrm{mL}$ de tampão acetato de potássio $(50 \mathrm{mM} / \mathrm{pH} 5,0)$ contendo $1 \mathrm{mM}$ EDTA. Os extratos foram centrifugados a $9000 \mathrm{~g}$ por cinco min a $-4{ }^{\circ} \mathrm{C}$ e o sobrenadante foi transferido para tubos Eppendorf e armazenado a $-80{ }^{\circ} \mathrm{C}$ (Dann \& Deverall, 2000). Os sobrenadantes foram utilizados para se avaliar a atividade de $\beta$-1,3-glucanase, peroxidase e teor de proteína solúvel.

\section{Atividade de $\beta$-1,3-glucanase (E.C. 3.2.1.29)}

A atividade de $\beta$-1,3-glucanase foi avaliada pela dosagem da glicose liberada com a hidrólise da laminarina (Tuzun et al., 1989). Para isto, pipetou-se para tubos de ensaio, $25 \mu \mathrm{L}$ do extrato enzimático; $200 \mu \mathrm{L}$ de tampão acetato de potássio $(0,1 \mathrm{M} / \mathrm{pH} 4,8)$ e $200 \mu \mathrm{L}$ de laminarina $(15 \mathrm{mg} / \mathrm{mL})$. Este material foi incubado a $37^{\circ} \mathrm{C}$ por $30 \mathrm{~min}$, e em seguida, acrescentou-se 1,0 $\mathrm{mL}$ de reagente de Somogy (Somogy, 1952), mais $10 \mathrm{~mL}$ de água e posto para agitar por 10 min. Após a agitação, o material foi aquecido a $100^{\circ} \mathrm{C}$ por $15 \mathrm{~min}$ e resfriado em banho de gelo. Acrescentou-se 1,0 mL de reagente Nelson (Somogy, 1952), $25 \mathrm{~mL}$ de água destilada sob agitação por $15 \mathrm{~min}$. Em seguida, foram realizadas leituras espectofotométricas a $760 \mathrm{~nm}$ e comparadas com padrão de glicose. A curva padrão de glicose foi preparada como adição de padrão, da mesma forma das amostras, substituindo-se a laminarina por soluções de glicose (0 - 200 $\mathrm{mg} / \mathrm{L})$.

\section{Extração da Peroxidade (E.C. 1.11.1.7)}

A atividade da peroxidase foi estimada com base na avaliação do $\Delta$ de absorbância proporcionada com oxidação do guaiacol $\left(\mathrm{C}_{3} \mathrm{H}_{8} \mathrm{O}_{2}\right)$ em presença do peróxido de hidrogênio (Dann \& Deverall, 2000). Para o desenvolvimento da reação, pipetou-se para uma cubeta espectofotométrica, 50 $\mu \mathrm{L}$ de guaiacol $(0,02 \mathrm{M}), 0,5 \mathrm{~mL}$ de peróxido de hidrogênio $(0,38 \mathrm{M})$ e $2,0 \mathrm{~mL}$ de tampão fosfato $(0,2 \mathrm{M} / \mathrm{pH} 5,8)$. Agitou-se levemente esta mistura, a qual serviu para zerar o espectrofotometro. Em seguida, acrescentou-se $50 \mu \mathrm{L}$ do extrato enzimático, agitou-se suavemente e procedeu-se a leitura espectofotométrica no comprimento de onde de 470 $\mathrm{nm}$, por um período de um minuto, com intervalo de $10 \mathrm{~s}$.

\section{Fenilalanina Amônia Liase (E.C. 4.3.1.5) Preparo do extrato}

Pesou-se $1,0 \mathrm{~g}$ de folhas correspondente a cada tratamento, transferiu-se para almofariz previamente gelado, acrescentou-se $6,0 \mathrm{~mL}$ do tampão de extração, a $4{ }^{\circ} \mathrm{C}$, e macerou-se a mistura completamente, a qual foi centrifugada em seguida a $6000 \mathrm{~g}$ por $10 \mathrm{~min}$ a $4^{\circ} \mathrm{C}$. O sobrenadante foi diluído antes da análise da atividade enzimática e da determinação da proteína solúvel, pipetando-se $200 \mu \mathrm{L}$ do mesmo e acrescentando-se $5 \mathrm{~mL}$ do tampão de extração. Este foi preparado com uma mistura de 22,2 $\mathrm{g}$ de Tris; 0,37 $\mathrm{g}$ de EDTA; 85,5 g de sacarose; $10 \mathrm{~g}$ de PVP e completou-se o volume para $1000 \mathrm{~mL}$ de água destilada, após ajustar o $\mathrm{pH}$ para 8,0 com ácido clorídrico 2,0 N.

\section{Determinação da atividade enzimática}

A atividade da PAL foi avaliada com base na diferença de absorbância resultante da conversão da fenilalanina em ácido trans-cinâmico (Hyodo et al., 1978). Para isto pipetouse para tubos de ensaio, $1,5 \mathrm{~mL}$ de cada extrato enzimático, acrescentou-se $1,0 \mathrm{~mL}$ do tampão de extração e $0,5 \mathrm{~mL}$ de fenilalanina $(49,6 \mathrm{mg} / \mathrm{mL})$ ou água destilada na prova em "branco". A mistura foi incubada a $40{ }^{\circ} \mathrm{C}$ por uma hora, interrompendo-se a reação com banho de gelo e procedendose as leituras espectofotométricas a $290 \mathrm{~nm}$

\section{Extração de Proteínas Solúveis}

$\mathrm{O}$ teor de proteína solúvel foi determinado colorimetricamente pelo método descrito por Bradford (1976). Para esta determinação, pipetou-se para tubos de ensaio, $200 \mu \mathrm{L}$ do extrato enzimático, acrescentou-se 2,0 $\mathrm{mL}$ do reagente "coomassie brilliant blue" (CBB), agitou-se suavemente cada tubo de ensaio e procedeu-se as leituras em espectofotômetro, no comprimento de onda de 595 $\mathrm{nm}$. As leituras das amostras correspondentes aos extratos enzimáticos foram convertidos em concentração de proteína solúvel, por comparação com as leituras de soluções padrões de albumina de soro bovino (BSA) nas concentrações de 0 , $25,50,100,150$ e $200 \mathrm{mg} / \mathrm{L}$. O reagente CBB foi preparado dissolvendo-se $0,10 \mathrm{~g}$ de "coomassie brilliant blue" G250 em $50 \mathrm{~mL}$ de álcool etílico absoluto, em seguida acrescentando-se $100 \mathrm{~mL}$ de ácido ortofosfórico $(\mathrm{d}=1,71$ g. $\left.\mathrm{mL}^{-1}\right)$ e $850 \mathrm{~mL}$ de água destilada.

\section{RESULTADOS E DISCUSSÃO}

Efeito de indutores em plantas de caupi inoculadas com Fusarium oxysporum f. sp. tracheiphilum

Os resultados apresentados na Tabela 1 indicam que ocorreu ativação de resistência sistêmica, mediada pelos indutores abióticos ASM, quitosana e BABA.

$\mathrm{Na}$ cultivar BR-17 Gurguéia, suscetível a $F$. oxysporum f. sp. tracheiphilum, foi observado diferença significativa entre os indutores e a testemunha, não ocorrendo diferença entre os indutores em relação à escala de notas, embora ASM tenha apresentado menor índice de 
TABELA 1 - Severidade da murcha de Fusarium oxysporum f. sp. tracheiphilum em plantas de caupi, tratadas com indutores abióticos, medida através de escala de notas, índice de doença e percentagem de controle, 25 dias após a germinação

\begin{tabular}{ccccc}
\hline \hline CULTIVAR & INDUTOR & $\begin{array}{c}\text { ESCALA DE } \\
\text { NOTA }\end{array}$ & $\begin{array}{c}\text { ÍNDICE DE } \\
\text { DOENÇA (\%) }\end{array}$ & $\begin{array}{c}\text { PERCENTAGEM DE } \\
\text { CONTROLE (\%) }\end{array}$ \\
\hline BR -17 & & & & \\
Gurguéia & ASM & $1,91 \mathrm{~b}$ & $21,41 \mathrm{~b}$ & 68,90 \\
& Quitosana & $2,18 \mathrm{~b}$ & $23,82 \mathrm{~b}$ & 65,40 \\
& BABA & $2,71 \mathrm{~b}$ & $29,57 \mathrm{~b}$ & 57,05 \\
& Testemunha & $6,20 \mathrm{a}$ & $68,85 \mathrm{a}$ & - \\
& & & & \\
IPA-206 & ASM & $1,72 \mathrm{~b}$ & $18,76 \mathrm{~b}$ & 71,59 \\
& Quitosana & $3,14 \mathrm{~b}$ & $34,61 \mathrm{~b}$ & 47,59 \\
& BABA & $3,18 \mathrm{~b}$ & $35,00 \mathrm{~b}$ & 47,00 \\
& Testemunha & $609 \mathrm{a}$ & $6604 \mathrm{a}$ & - \\
\hline CV (\%) & & 20,72 & 24,55 & \\
\hline
\end{tabular}

Médias seguidas das mesmas letras nas colunas não diferem entre si, pelo teste de Tukey, ao nível de 5\% de probabilidade.

doença seguido de quitosana e BABA. A cultivar IPA-206 apresentou comportamento semelhante em relação a escala de notas, ocorrendo diferença significativa entre indutores e a testemunha, e dentre os indutores, ASM proporcionou nota mais baixa, embora sem diferir estatisticamente dos demais indutores.

Comparando-se as testemunhas entre si, isto é, as plantas tratadas somente com água destilada, verifica-se que apresentaram índices de doença de $68,85 \%$ e 66,04 $\%$ para BR-17 Gurguéia e IPA-206, respectivamente, após 18 dias da inoculação. Embora, na época de avaliação, os índices de doença observados tenham sido muito próximos, a expressão dos sintomas na cultivar IPA-206 foi mais tardia que na BR-17 Gurguéia.

O uso do ASM, aos cinco dias após a germinação, proporcionou um controle da murcha de fusário nas duas cultivares testadas, sendo que a cultivar BR-17 Gurguéia, suscetível à murcha de fusário, apresentou um controle de 68,90 $\%$, enquanto a cultivar IPA-206, com resistência intermediária, apresentou $71,59 \%$ de controle. A ativação da resistência em cultivares suscetíveis, foi também observada por Dann \& Deverall (2000) em ervilha tratada com ASM e demonstrada pela menor percentagem de área foliar afetada por $U$. viciaefabae: $1,5 \%$ comparado a $9,39 \%$ do controle.

A ação do ASM como indutor de resistência tem sido comprovada em diversas plantas cultivadas, envolvendo vários patossistemas, destacando-se entre estas: o cacau (Theobroma cacao L.), cafeeiro (Coffea arábica L.), caupi e tomateiro (Resende et al., 2000; Marchi et al., 2002; Rodrigues \& Coelho, 2002; Gurgel, 2004).

$\mathrm{O}$ indutor quitosana proporcionou o segundo maior controle da murcha de Fusarium, com 65,40 \% para a cultivar BR-17 Gurguéia e 47,59 \% para a cultivar IPA-206.
É importante ressaltar que a maior percentagem de controle foi observada na cultivar de caupi, com maior suscetibilidade ao patógeno, indicando que esse indutor possui a habilidade de elicitar a resposta de defesa natural da planta. Resultados semelhantes foram obtidos por Benhamou et al. (1994) no controle da murcha de fusário do tomateiro, através do tratamento de sementes com quitosana.

A indução de resistência mediada pelo quitosana ocorre pela ligação dessa molécula ao receptor, no hospedeiro, imitando um ataque fúngico, e a célula sensibilizada envia sinais ao núcleo, que elicita respostas genéticas múltiplas e processos biológicos que visam a inibição da infecção. Por outro lado, supõe-se que essa molécula, devido a diferença de carga entre DNA (negativo) e quitosana (positivo), se associa ao DNA, ativando genes responsáveis pela defesa da planta, conduzindo a uma resposta genética múltipla (Safescience, 2001).

Dentre os indutores avaliados, o BABA foi o menos efetivo no controle da murcha de fusário do caupi. Resultados obtidos por Zimmerli et al. (2001), comprovaram que o tratamento do solo com BABA foi efetivo contra Botrytis cinerea Pers. causador do mofo cinzento em Arabidopsis, reduzindo a superfície da área necrosada e a incidência da doença, quando comparada com a testemunha. A indução de resistência pelo uso de BABA já foi comprovado em alguns patossistemas envolvendo Fusarium, como tomate e Fusarium oxysporum f. sp. lycopersici W.C. Snyder \& H.N. Hansen e milho (Zea mays L.) e Fusarium moniliforme J. Sheld. (Jakab et al., 2001), porém, este pode ser o primeiro relato de uso do indutor ácido $\beta$-aminobutírico envolvendo caupi e $F$. oxysporum f. sp. tracheiphilum, uma vez que não foi encontrado na literatura disponível outro relato semelhante. 
Ainda não está claro o modo pelo qual o indutor BABA age, se pela rota metabólica dependente do ácido salicílico, induzindo a ação de genes relacionados com as proteínas $\mathrm{PR}$, ou se pela rota do jasmonato/etileno, independente do ácido salicílico, ou pelas duas vias. Porém, segundo Jakab et al. (2001), a proteção efetiva desse indutor é devido a uma potencialização dos mecanismos naturais de defesa da planta contra o patógeno.

\section{Efeito de indutores sobre a atividade enzimática. $\beta$-1,3-glucanase}

Aatividade de $\beta$-1,3-glucanase, avaliada aos cinco dias após a inoculação com o patógeno, diferiu significativamente em resposta ao ASM, em ambas as cultivares, sendo este indutor o que proporcionou maior atividade desta enzima (Figura 1A).

Nas cultivares BR-17 Gurguéia e IPA-206 induzidas pelo ASM, a atividade desta enzima foi de 7,60 e 14,63 $\Delta$ $\mathrm{ab}_{760} \mathrm{~min}^{-1} \mathrm{mg}$, respectivamente, cinco dias após a inoculação. Quando a atividade enzimática foi avaliada aos 10 dias após a inoculação, a cultivar BR-17 Gurguéia também mostrou diferença significativa entre a testemunha e o tratamento com ASM. No entanto, a cultivar IPA-206 não apresentou diferença significativa entre a testemunha a quaisquer dos indutores. Aos 10 dias, a atividade da $\beta$-1,3-glucanase foi 7,98 e 4,21 $\Delta \mathrm{ab}_{760} \mathrm{~min}^{-}$ ${ }^{1}$.mg, respectivamente, para BR-17 Gurguéia e IPA-206. Como se pode observar, na cultivar BR-17 Gurguéia, induzida pelo ASM, a atividade da $\beta$-1,3-glucanase permaneceu praticamente constante entre cinco e 10 dias. Este resultado sugere que após a ativação da resistência sistêmica adquirida pelo ASM em cultivares suscetíveis, essa proteína PR permaneceu ativa na planta durante o período, proporcionando maior proteção contra $F$. oxysporum f. sp. tracheiphilum.

Na cultivar IPA-206, com resistência intermediária ao patógeno, foi observado um pico alto da enzima aos cinco dias após a inoculação, seguido de uma queda significativa aos 10 dias, indicando que a atividade dessa hidrolase não ocorreu de forma constante.

A relação entre resistência sistêmica e hidrolases como $\beta$-1,3-glucanase e quitinase, sempre esteve baseada no fato de que $\beta$-1,3-glucana e quitina são os maiores componentes da parede celular de muitos fungos e que essas enzimas podem hidrolizar a parede celular desses patógenos in vitro, mesmo em oomicetos. Tuzun et al. (1989) observaram uma correlação positiva entre indução de resistência a Phytophthora parasitica Dastur em fumo e ativação de $\beta$-1,3-glucanase, sugerindo que as plantas induzidas ficam sensibilizadas e respondem mais rapidamente que as plantas controle e, que $\beta$-1,3-glucanase é um componente da resposta de defesa da planta por restringir o desenvolvimento do patógeno no tecido foliar.

$\mathrm{Na}$ ativação da resistência sistêmica adquirida, a formação de proteínas PR estão envolvidas em uma rota de transdução de sinais, dependente do ácido salicílico, para a expressão da proteína chave NPR1. Nesse caso, análogos do ácido salicílico como ASM podem entrar nessa rota do metabolismo das plantas, induzindo a resistência sistêmica e, segundo Métraux (2001), esse indutor pode ter função dupla nessa rota, tanto induzindo diretamente ou potencializando genes envolvidos na reação de defesa da planta.

Foi observado um efeito menor dos indutores BABA e quitosana na ativação de $\beta$-1,3-glucanase, quando comparado com ASM, embora, aos cinco dias após inoculação a atividade enzimática tenha sido maior que a detectada aos 10 dias, não diferindo estatisticamente da testemunha, nas cultivares testadas.

\section{Peroxidase}

Aos cinco dias após a inoculação com o patógeno, a atividade da peroxidase aumentou apenas na cultivar IPA206, como efeito do ASM (Figura 1B). No entanto, aos 10 dias, este efeito foi verificado tanto na cultivar IPA-206 como na BR-17 Gurguéia, em resposta ao mesmo indutor. A cultivar IPA-206, quando tratada com ASM, apresentou atividade enzimática de 12,71 e $9,42 \Delta \mathrm{ab}_{470} \mathrm{~min}^{1} \cdot \mathrm{mg}$, respectivamente aos cinco e 10 dias após a inoculação. Com os indutores BABA e quitosana a atividade da peroxidase não diferiu da testemunha, nas duas cultivares e diferentes épocas. Este resultado suporta a hipótese de que este não é o mecanismo pelo qual esses indutores ativam a resistência em caupi. Diferentemente, Oliveira et al. (2001), estudaram o comportamento de genótipos de caupi resistentes e suscetíveis à antracnose e meloidoginose quanto à produção de peroxidase e observaram que a cultivar TE97-4111E resistente a Meloidogyne incognita (Kofoid \& White) Chitwood, apresentou um aumento significativo da atividade peroxidásica em resposta a infecção, sugerindo a participação dessa enzima no mecanismo de defesa das plantas.

Diversos autores relacionaram a atividade da peroxidase em feijoeiro (Phaseolus vulgaris L.) com a resistência sistêmica. Siegrist et al. (1997) verificaram a alta produção enzimática $23,80 \Delta \mathrm{ab}_{470} \cdot \mathrm{min}^{-1} \mathrm{mg}$ em fluídos intercelulares de folhas de feijoeiro comum comparado com $8,0 \Delta \mathrm{ab}_{470} \cdot \mathrm{min}^{-1} \mathrm{mg}$ no controle, induzidos com ASM e inoculados com Uromyces appendiculatus (Pers.) Link. A resistência relaciona-se, provavelmente, ao fato do patógeno crescer no apoplasto, onde ocorre a atividade enzimática. Xue et al. (1998) usaram isolados de Rhizoctonia binucleada (NBS) não patogênicos como indutores e detectaram um aumento da atividade de peroxidase em tecido de feijão não inoculado, conferindo proteção contra Rhizoctonia solani Kühn e Colletotrichum lindemuthianum (Sacc. \& Magnus). Dann \& Deverall (2000) constataram que a atividade da peroxidase foi induzida, seis dias após a inoculação, apenas nas folhas de ervilha inoculadas com isolado avirulento de Pseudomonas syringae pv. pisi Sacketti e não de forma sistêmica.

A indução da atividade de peroxidases, pelo ASM, foi também relatada por Cavalcanti (2000) em cacau contra Verticillium dahliae Kleb. sendo detectada em um nível mais alto por período de tempo mais longo. Fernandes (1998) selecionou a cultivar Vita-3 de caupi pela maior produção constitutiva de duas peroxidases (catiônica e aniônica) e observou aumento da atividade enzimática, após tratamento 
com ácido salicílico, principalmente, da peroxidase aniônica e, sugeriu que essa enzima poderia estar relacionada com a resistência das plantas.

A atividade peroxidásica a partir da indução advém de uma seqüência de eventos e sinais, partindo de uma isoforma pré-existente, catalizando o último passo enzimático da biossíntese da lignina, servindo como barreira ao patógeno, ou mesmo interagindo com a quitina da parede celular de muitos fungos atuando conjuntamente com $\beta$-1,3-glucanase (Fernandes, 1998).

\section{Fenilalanina Amônia Liase (PAL)}

Aos cinco dias após a inoculação, a atividade da PAL na cultivar BR-17 Gurguéia não diferiu estatisticamente entre a testemunha e os indutores, enquanto que na cultivar IPA-206, o ASM proporcionou aumento na atividade desta enzima (Figura 1C). Aos 10 dias após a inoculação, apenas ASM mostrou efeito significativo sobre a ativação da PAL, em ambas as cultivares. Na BR-17 Gurguéia ocorreu um pequeno aumento na atividade da PAL, do quinto ao décimo dia após a inoculação, ao contrário do que ocorreu com os demais indutores. A atividade da PAL elicitada por ASM aos 10 dias após a inoculação foi de 1,49 e $1,99 \Delta \mathrm{ab}_{290} \cdot \mathrm{min}^{-1} \mathrm{mg}$, respectivamente, para IPA206 e BR-17 Gurguéia.

Aatividade da PALestárelacionada comaresistência de plantas a patógenos, notadamente, por estar envolvida no primeiro passo da síntese dos fenilpropanóides, com participação de fenilalanina e sua conversão em ácidotranscinâmico, catalizada pela PAL, resultando em compostos como fitoalexinas e, principalmente, lignina, que confere maior resistência à parede celular das plantas aos patógenos (Nakazawa et al., 2001). A baixa atividade encontrada em caupi, pode estar relacionada com a época de realização da avaliação, sendo que o intervalo entre a inoculação e o preparo do extrato foliar pode ter sido longo e o pico enzimático ter ocorrido em um prazo mais curto, apesar de tratar-se de um patógeno vascular. Na avaliação da atividade dessa enzima, Latunde-Dada \& Lucas (2001) detectaram a maior atividade em hipocótilo da cultivar de caupi IT82E-60, 18 h após a inoculação com $C$. destructivum, decrescendo rapidamente, em seguida. Também foi confirmado por outros autores, que mesmo a ativação da PAL sendo induzida por outros fatores, como ferimento (Saltveit, 2000) ou luz (Chen et al., 2002), o pico da atividade enzimática ocorre entre 24 a 48 h no máximo após a indução. E a antecipação do pico dessa enzima, provavelmente, pode estar relacionada com a sua função no início da rota biossintética da lignina. Por outro lado, trabalhos com indutores bióticos e abióticos em bananeira (Musa spp) e feijoeiro tem evidenciado atividade tardia da PAL, aos seis, oito e 12 dias após a indução (Campos et al., 2003; Saravanan et al., 2004).

\section{Efeito de indutores abióticos na atividade de $\beta$-1,3-glucanase e índice da doença murcha de fusário em caupi}

Foi observada uma correlação inversa entre a ação

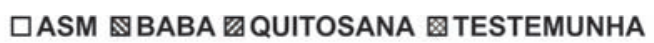
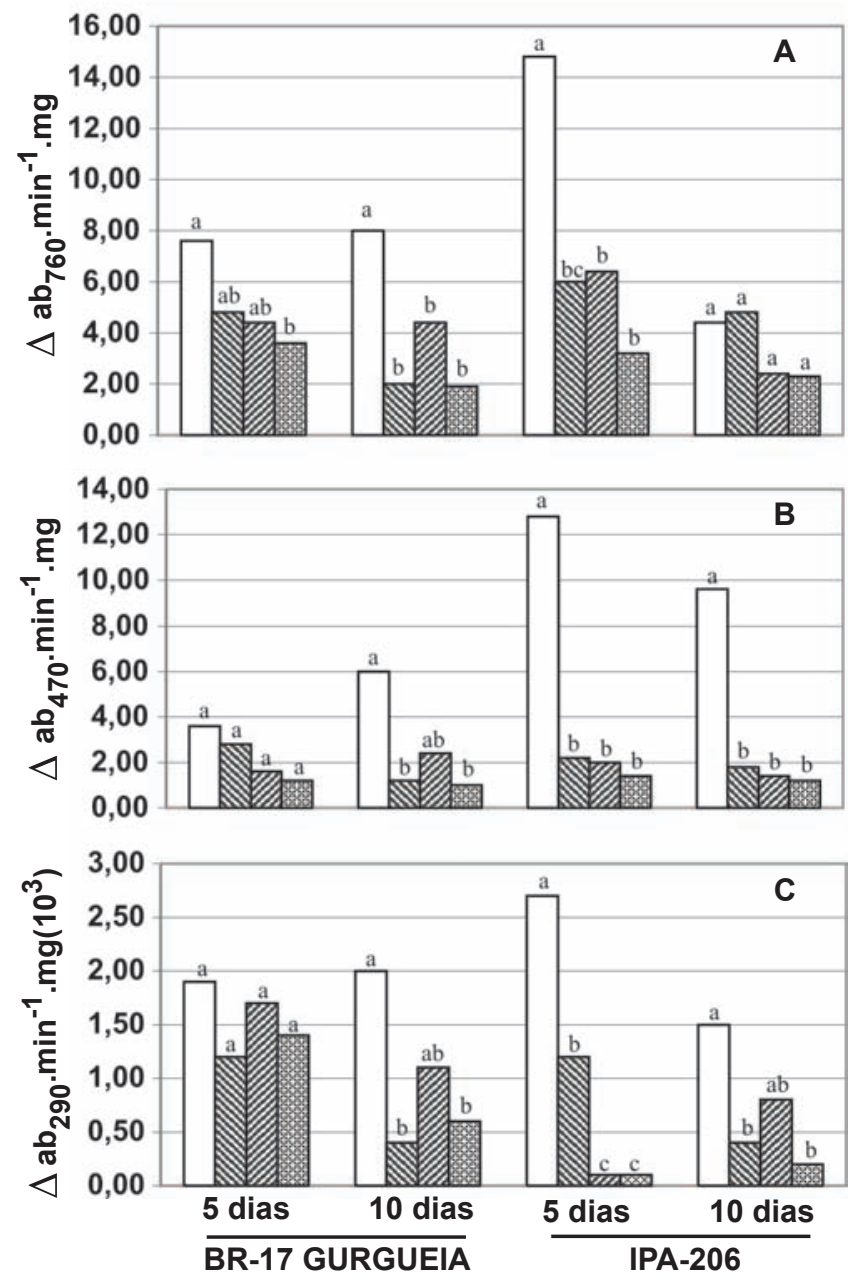

FIG. 1 - A. Atividade de $\beta$-1,3-glucanase; B. peroxidase; C. PAL em cultivares de caupi induzidas com ASM, BABA e quitosana, aos cinco e 10 dias após a inoculação com Fusarium oxysporum f. sp. tracheiphilum. Médias seguidas por letras distintas diferem significativamente entre si pelo teste de Tukey, ao nível de $5 \%$ de probabilidade. $\mathrm{CV}=16,28 ; 26,96$ e $16,11 \%$, respectivamente.

dos indutores na atividade da $\beta$-1,3-glucanase, aos cinco dias após a inoculação, e o índice de doenças em ambas as variedades de caupi (Figura 2). Enquanto os índices de doença aumentaram com a seqüência ASM, quitosana e BABA, testemunha, a atividade da $\beta$-1,3-glucanase diminuiu nesta seqüência de tratamentos, confirmando a ação dos indutores no controle da doença, inclusive com maior eficácia para o ASM. A comparação com $\beta$-1,3-glucanase, deve-se ao fato desta proteína PR estar diretamente relacionada à redução da severidade das doenças.

$\mathrm{O}$ indutor ASM proporcionou menor índice de doença nas cultivares BR-17 Gurguéia e IPA-206, respectivamente, com 21,41 e $18,76 \%$, correspondendo, também, a maior indução de produção enzimática nas duas cultivares, com 7,60 e 14,63 $\Delta \mathrm{ab}_{760} \mathrm{~min}^{-1} \mathrm{mg}$, 


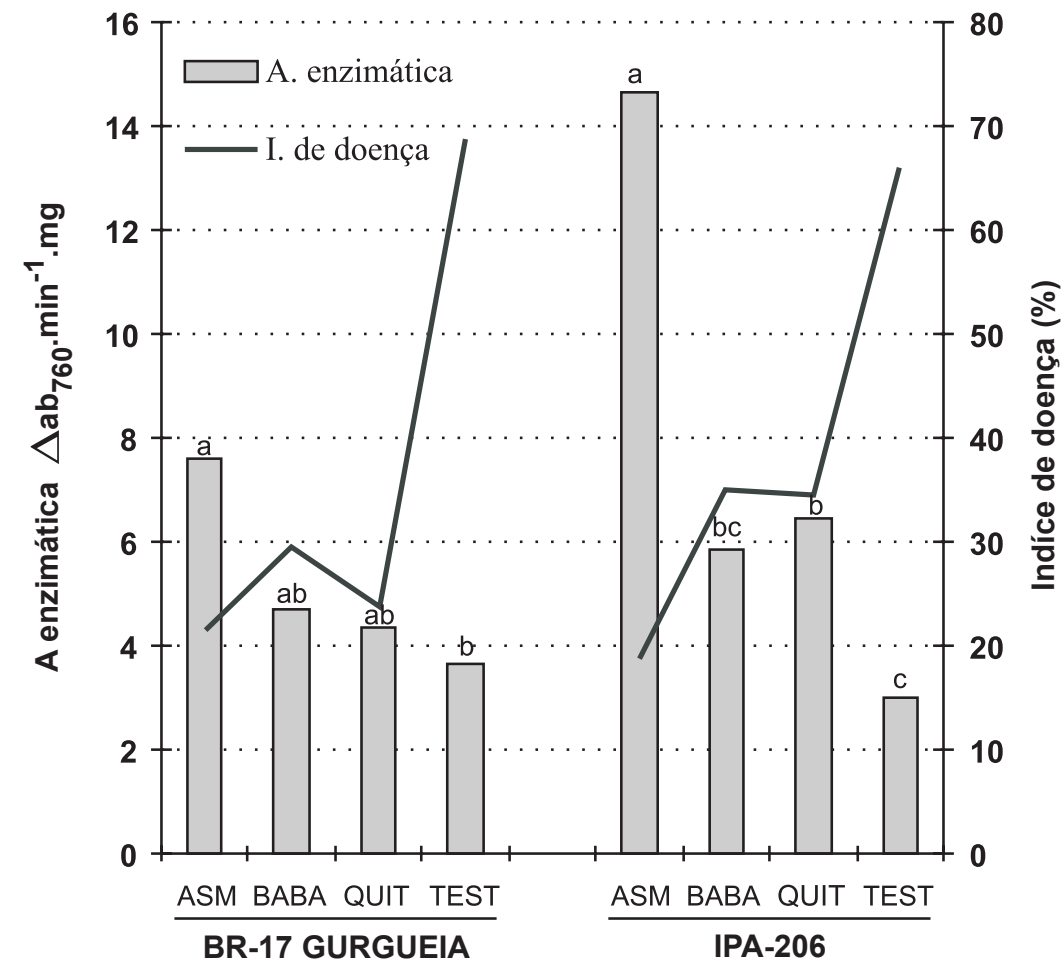

FIG. 2 - Efeito do indutores ASM, BABA e quitosana na produção de $\beta-1,3$ glucanase, aos 5 e 10 dias após a inoculação, no controle da murcha de fusário em caupi. Médias seguidas por letras distintas diferem significativamente entre pelo teste de Tukey, ao nível de $5 \%$ de probabilidade. $\mathrm{CV}=24,55 \%$ respectivamente, diferindo significativamente das testemunhas. Os indutores BABA e quitosana induziram maiores índices de doença, em relação ao ASM, porém menor em relação a testemunha, apesar de não diferirem estatisticamente e, conseqüentemente, menores atividades de $\beta$-1,3-glucanase, provavelmente, pelo fato desses indutores atuarem na resistência sistêmica adquirida desencadeando outros mecanismos, e não necessariamente, a síntese de proteínas PR.

A relação entre a ação do indutor ASM na redução da severidade associado com a produção de proteínas PR foi demonstrado por Dann \& Deverall (2000) em ervilha, contra o patógeno Mycosphaerella pinodes (Berk. et Blox.) Stone, minimizando a doença e aumentando a atividade de $\beta$-1,3-glucanase e quitinase, confirmando o envolvimento dessas enzimas na resistência sistêmica adquirida. Tuzun et al. (1989) observaram que plantas de fumo previamente injetadas com esporângios de Peronospora tabacina D.B. Adan foram protegidas após subseqüente inoculação com o patógeno, promovendo um controle de até $95 \%$ da doença, relacionado com o aumento da atividade de $\beta$-1,3-glucanase entre dois e seis dias após a indução.

$\mathrm{O}$ uso de indutores, especialmente o ASM, permitiu a redução da severidade da murcha de fusário em caupi, desencadeando a produção de proteína PR $\beta$-1,3-glucanase como um mecanismo bioquímico da resistência sistêmica adquirida, podendo ser usado no manejo da doença na cultura do caupi.

\section{REFERÊNCIAS BIBLIOGRÁFICAS}

ALBUQUERQUE, M.P., COELHO, R.S.B. \& PEREZ, J.O. Avaliação de linhagens e cultivares de caupi (Vigna unguiculata) em relação a Fusarium oxysporum f. sp. tracheiphilum. Caderno Ômega 10:5-7. 2001.

ASSUNÇÃO, I.P., MICHEREFF, S.J., MIZUBUTI, E.S.G. \& BROMMONSCHENKEL, S.H. Influencia da intensidade da murcha de fusário no rendimento do caupi. Fitopatologia Brasileira 28:615-619. 2003.

BALARDIN, R.S. PASTOR-CORRALES, M.A. \& OTOYA, M.M. Resistência de germoplasma de feijão (Phaseolus vulgaris L.) a Fusarium oxysporum f. sp. phaseoli. Fitopatologia Brasileira 17:102-103. 1990.

BENHAMOU, N. LAFONTAINE, P.J. \& NICOLE, M. Induction of systemic resistance to Fusarium crow and root rot in tomato plants by seed treatment with chitosan. Phytopathology 84:14321444. 1994.

BENHAMOU, N., KLOEPPER, J.W. \& TUZUN, S. Induction of resistance against Fusarium wilt of tomato by combination of chitosan with an endophytic bacterial strain: ultrastructure and cytochemistry of the host response. Planta 204:153-168. 1998.

BRADFORD, M.M. A rapid and sensitive method for the quantitation of microgram quantities of protein utilizing the principle of protein-dye binding. Analytical Biochemistry 72:248254. 1976.

CAMPOS, A.D., FERREIRA, A.G., HAMPE, M.M.V., ANTUNES, I.F., BRANCÂO, N., SILVEIRA, E.P., SILVA, J.B. \& OSORIO, 
V.A. Induction of chalcone synthase and phenylalanine ammonialiase by salicylic acid and Colletotrichum lindemuthianum in common bean. Brazilian Journal of Plant Physiology 15:129-134. 2003.

CAVALCANTI, L.S. Indução de resistência a Verticillium dahliae Kleb. em plântulas de cacaueiro (Theobroma cacao L.) cv. Thebroma, por benzothiadiazole (BTH). (Dissertação de Mestrado). Lavras, MG. Universidade Federal de Lavras. 2000.

CHEN, Y., SHIN, J. \& LIU, Z. Effect of light on peroxidase and lignin synthesis in mungbean hypocotyls. Plant Physiology and Biochemistry 40:33-39. 2002.

COLE, D.L. The efficacy of acibenzolar-S-methyl, an inducer of systemic acquired resistance, against bacterial and fungal disease of tobacco. Crop Protection 18:267-273. 1999.

DANN, E.K. \& DEVERALL, B.J. Activation of systemic disease resistance in pea by an avirulent bacterium or benzothiadiazole, but not by a fungal leaf spot pathogen. Plant Pathology 49:324-332. 2000.

DURRANT, W.E. \& DONG, X. Systemic Acquired Resistance. Annual Review of Phytopathology 42:185-209. 2004.

FERNANDES, C.F. Estudo da atividade peroxidásica em folhas primárias de feijão-de-corda [Vigna unguiculata (L.) Walp.] cv. Vita 3. (Dissertação de Mestrado). Fortaleza, CE. Universidade Federal do Ceará. 1998.

GURGEL, L.M.S. Resistência sistêmica induzida em cultivares de tomateiro à murcha de fusário: indutores químicos, mecanismos de defesa envolvidos e eficiência de controle no campo. (Tese de Doutorado). Recife, PE. Universidade Federal Rural de Pernambuco. 2004.

HAMMERSCHMIDT, R. Cytological and biochemical aspects of the induced resistance response of cucumber to fungal pathogens. Fitopatologia Brasileira 26: 253-254. 2001. (Resumo)

HYODO, H.; KURODA, H. \& YANG, S.F. Induction of phenylalanine ammonia-lyase and increase in phenolics in lettuce leaves in relation to the development of russet spotting caused by ethylene. Plant Physiology 62:31-35. 1978.

JAKAB, G., COTTIER, V., TOQUIN, V., RIGOLI, G., ZIMMERLI, L., MÉTRAUX, J.P. \& MAUCH-MANI, B. $\beta$-aminobutyric acidinduced in plants. European Journal of Plant Pathology 107:29-37. 2001.

LATUNDE-DADA, A.O. \& LUCAS, J.A. The plant defence activador acibenzolar-S-methyl primes cowpea [Vigna unguiculata (L.) Walp.] seedlings for rapid induction of resistance. Physiological and Molecular Plant Pathology 58:199-208. 2001.

MARCHI, C.E., BORGES, M.F.\& RESENDE, M.L.V. Proteção induzida por benzotiadiazole contra a ferrugem alaranjada (Hemileia vastatrix) em cafeeiro. Ciência e Agrotecnologia 26:1103-1106. 2002.

MENEZES, M. Relações entre Fusarium oxysporum f. sp. vasinfectum (Atk.) Snyder. \& Hansen e diferentes hospedeiros não suscetíveis. (Dissertação de Mestrado). Piracicaba, SP. ESALQ, Universidade de São Paulo. 1972.

MÉTRAUX, J.P. Systemic acquired resistance and salicylic acid: current state of knowledge. European Journal of Plant Pathology
107:13-18. 2001.

NAKAZAWA, A., NOZUE, M. \& YASUDA, H. Expression pattern and gene structure of phenylalanine ammonia-lyase in Pharbitis nil. Journal of Plant Research 114:323-328. 2001.

OLIVEIRA, J.T.A., ANDRADE, N.C., MIRANDA, A.S.M., BARRETO, A.L.H., MELO, V.M.M., FERNANDES, C.F., VASCONCELOS, I.M., SILVEIRA, J.A.G., CAVALCANTI, F.R., FREIRE-FILHO, F.R., FREIRE, F.C.O. \& GONÇALVES, F.J.T. Atividades peroxidásica e $\beta-1,3$ glucanásica elicitadas por agentes bióticos causadores de doenças e pelo estresse hídrico em feijão-decorda [Vigna unguiculata (L.) Walp.]. Anais: V Reunião Nacional de pesquisa de Caupi-V RENAC, Teresina, PE. 2001. pp. 19-23.

RESENDE, M.L., NOJOSA, J.B.A., AGUILAR, M.A.G., SILVA, L.H.C.P., NIELLA, G.R., CARVALHO, G.A., GIOVANNI, G. \& CASTRO, M.C. Perspectivas da indução de resistência em cacaueiro contra Crinipellis perniciosa através do benzotiadiazole (BTH). Fitopatologia Brasileira 25:149-156. 2000.

RODRIGUES, A.A.C. \& COELHO, R.S.B. Efeito de dosagens e épocas de aplicação de acibenzolar-S-methil em plantas de caupi na indução de resistência a Fusarium oxysporum f. sp. tracheiphilum. Fitopatologia Brasileira 27:157. 2002. (Resumo)

SAFESCIENCE. Mode of action and elicitation of plant defense responses. 2000. http://www/safescience.com/agriculture/ elexamoti.html>. Consulta feita em: 09/12/2001.

SALTVEIT, M.E. Wound induced changes in phenolic metabolism and tissue browning are altered by heat shock. Postharvest Biology and Technology 21:61-69. 2000.

SARAVANAN, T., BHASKARAN, R. \& MUTHUSAMY, M. Pseudomonas fluorescens induced enzymological changes in banana roots (Cv. Rasthali) against Fusarium wilt. Plant Pathology Journal 3:72-80. 2004.

SCHOONHOVEN, A.V. \& PASTOR-CORRALES, M.A. Standard system for the evaluation of beans germplasm. Cali. Centro International de Agricultura Tropical - CIAT. 1987.

SIEGRIST, J., GLENEWINKEL, D., KOLLE, C. \& SCHIMIDTKE, $\mathrm{M}$. Chemically induced resistance in green bean against bacterial and fungal pathogens. Journal of Plant Disease and Protection 104:599-610. 1997.

SOMOGY, M. Notes on sugar determination. Journal Biology and Biochemistry 195:19-23. 1952.

TUZUN, S., RAO, N.M., VOGELI, U., SCHARDL, C.L. \& KÚC, J. Induced systemic resistance to blue mold: early induction and accumulation of $\beta$-1,3-glucanase, chitinase, and other pathogenesisrelated proteins (b-proteins) in immunized tabacco. Physiology and Biochemistry 79:979-983. 1989.

XUE, L., CHAREST, P.M. \& JABAJI-HARE, H. Systemic induction of peroxidase, 1,3- $\beta$-glucanase, and resistance in bean plants by binucleate Rhizoctonia species. Phytopathology 88:359365. 1998.

ZIMMERLI, L., MÉTRAUX, J.P. \& MAUCH-MANI, B. $\beta$ aminobutyric acid-induced protection of Arabidopsis against the necrotrofic fungus Botrytis cinerea. Plant Physiology 126:517-523. 2001. 